\title{
Methylphenidate improved symptoms in children and adolescents with conduct disorder independent of ADHD severity
}

\author{
Klein RG, Abikoff H, Klass E, et al. Clinical efficacy of methylphenidate in conduct disorder with and without attention deficit \\ hyperactivity disorder. Arch Gen Psychiatry 1997 Dec;54:1073-80.
}

\section{Question}

Can methylphenidate improve symptoms in children with conduct disorder with and without attention deficit hyperactivity disorder $(\mathrm{ADHD})$ ?

\section{Design}

Randomised, double blind, placebo controlled trial with 5 weeks follow up.

\section{Setting}

Schools in New York State, USA.

\section{Patients}

84 children between 6 and 15 years of age (mean age 10 y, $89 \%$ boys) referred from schools and juvenile probation officers who had a modified DSM-III diagnosis of conduct disorder (lying could not qualify for diagnosis) and who were attending school. Children with substance disorders were excluded. $69 \%$ of children had comorbid ADHD. 74 children (88\%) completed the study (37 in each group).

\section{Intervention}

41 children were allocated to methylphenidate, preset titration, up to $60 \mathrm{mg} /$ day, in 2 divided doses. Dose could be adjusted based on adverse effects and clinical response. 43 children were allocated to matching placebo. All parents received weekly supportive counselling.

\section{Main outcome measures}

Clinician reports, and behaviour evaluated by parent and teacher and direct classroom observation.

\section{Main results}

Based on scores from the Conners Teacher Rating Scale and the Quay Revised Behaviour Checklist, teachers rated children in the methylphenidate group as being improved (except for socialised aggression) compared with those in the placebo group. Factor scores were improved for aggression, conduct problems, conduct disorder, inattentive/overactive, hyperactivity, and inattentive/passive ( $\mathrm{p}<0.001$ for all). Specific aspects of conduct disorder were affected by methylphenidate (eg, obscene language, attacks others, destroys property, and deliberately cruel). Favourable statistically significant methylphenidate effects were also obtained on parent factors, except for socialised aggression. Compared with the placebo group, more children in the methylphenidate group were viewed as improved by teachers, mothers, and psychiatrists $(\mathrm{p}<0.001$ for all) (table). The benefit of methylphenidate on global clinical improvement remained after controlling for initial $\mathrm{ADHD}$ ratings.

\section{Conclusion}

Short term treatment with methylphenidate improved symptoms in children and adolescents with conduct disorder independent of attention deficit hyperactivity disorder symptom severity.

Methylphenidate v placebo at 5 weeks

\begin{tabular}{lllll}
\hline Outcome & Methylphenidate & Placebo & RBI (95\% CI) & NNT (CI) \\
\hline $\begin{array}{c}\text { Improved } \\
\text { (psychiatrist } \\
\text { ratings) }\end{array}$ & $68 \%$ & $11 \%$ & $\begin{array}{l}474 \% \\
(144 \text { to } 1378)\end{array}$ & 2 (1 to 3) \\
\hline
\end{tabular}

*Abbreviations defined in glossary; RBI, NNT, and CI calculated from data in article.

Source of funding: in part, National Institute of Mental Health.

For correspondence: $\operatorname{Dr} R$ D Klein, Department of Clinical Psychology, Unit 80, New York State Psychiatric Institute, 722 West 168th Street, New York, NY 10032, USA. Fax +1 2125435966.

\section{Commentary}

This study by Klein et al confirms previous research that shows that the diagnosis of conduct disorder without comorbid ADHD ("pure" conduct disorder) is rare in clinical samples. Only $5 \%$ of referrals met criteria for conduct disorder but not for ADHD. This study also replicates numerous reports of the short term advantage of methylphenidate over placebo in improving ADHD and oppositional symptoms but not in increasing academic test scores.

The main conclusion of this study is that severity of anti-social behaviour was substantially reduced by methylphenidate independent of the drug's effects on ADHD. Two issues need to be considered in evaluating the findings. Firstly, the measures used to assess improvement cannot distin- guish whether the oppositional and aggressive behaviour occurred as a result of impulsivity or were more proactive in nature (ie, deliberate and pre-meditated). The former symptoms are the most closely related to core ADHD symptoms and the most likely to be reduced with successful treatment of ADHD. Moreover, no statistically significant benefit of methylphenidate was evident in socialised aggression. These aspects of conduct disorder may require longer treatment than the 5 weeks in this study or may not be responsive to stimulant medication at all. Secondly, no specific description is presented of the 15 children with conduct disorder but without ADHD. Although there are few of these children, they are the most informative with respect to specific drug effects on conduct disor- der. This small subgroup may account for the majority of the non-responders in this study.

The potential role of methylphenidate in the treatment of the mixed clinical presentation of ADHD and conduct disorder is supported by these data but not necessarily the role of stimulant medication in children who do not meet criteria for ADHD. Long term treatment studies of children with ADHD and conduct disorder will be needed before clinicians will know whether medication should be an important part of treatment for conduct disorder.

Russell Schachar, MD The Hospital for Sick Children Toronto, Ontario, Canada 